\title{
Kidney tumour (congenital mesoblastic nephroma - CMN) in a newborn
}

\author{
Rafał Krajewski', Grzegorz Maroszek' ${ }^{1}$, Agata M. Kawalec², Jan Godziński² \\ 'Students' Scientific Association, Wroclaw Medical University \\ ${ }^{2}$ Marciniak Hospital, Wroclaw
}

\section{ABSTRACT}

Introduction: Renal tumours account for over $6 \%$ of cancer diagnoses in children under 15 years old. Rarely they are diagnosed in newborns.

Case report: A Female neonate born through a caesarean section in the $39^{\text {th }}$ week of pregnancy with palpable pathological dense mass located in the abdominal cavity in the physical examination of abdomen just after the labour diagnosed as a kidney tumour (ultrasound examination, MRI) was admitted to the Department of Paediatric Surgery for surgical treatment - right-sided nephrectomy and biopsy of regional lymph nodes. The histopathological examination revealed congenital mesoblastic nephroma (classical type). After consultation with the paediatric surgeon, pediatric oncologist it was decided that the girl did not require chemotherapeutic treatment.

Conclusions: Congenital mesoblastic nephroma is one of the most frequent renal tumours in newborns and young infants. Most children with CMN have an excellent prognosis and are treated with nephrectomy with lymph node sampling.

KEY WORDS:

newborn, kidney tumour, congenital mesoblastic nephroma.

\section{INTRODUCTION}

Renal tumours account for over $6 \%$ of cancer diagnoses in children under 15 years old [1]. They include nephroblastoma (Wilms' tumour), renal cell carcinoma (RCC), clear cell carcinoma of the kidney (CCSK), rhabdoid tumour of the kidney (RTK), congenital mesoblastic nephroma, cystic renal tumour, and angiomyolipoma [1]. Among them Wilm's tumour is the most common. However, congenital mesoblastic nephroma (CMN) accounts for considerable number of cases of renal tumours - from $5 \%$ to $20 \%[2-4]$.

Incidence of congenital tumours is between 2 and 14 infants per 100,000 live births, so this is a rare pathology [5]. In recent years an increase in the number of congenital tumours is observed [6]. Among congenital tumours re- nal tumours account for 5-7.1\% [6]. Most of them is benign [6]. The most frequent histological types are congenital mesoblastic nephroma (CMN), nephroblastomatosis, the multilocular cystic nephroma [6].

\section{CASE REPORT}

A female neonate was born through a caesarean section in the $39^{\text {th }}$ week of the pregnancy (second pregnancy, second labour). During pregnancy foetal ultrasound was performed, but the pathology was not found.

After birth the child presented in general good state and obtained 10 points in APGAR scale. The birth weight was $3480 \mathrm{~g}$. The physical examination of abdomen just after the labour revealed the existence of a pathological dense mass located in the abdominal

\section{ADDRESS FOR CORRESPONDENCE:}

Agata M. Kawalec, Chair and Department of Hygiene, Marciniak Hospital, Wroclaw,

e-mail: agata_kawalec@wp.pl 


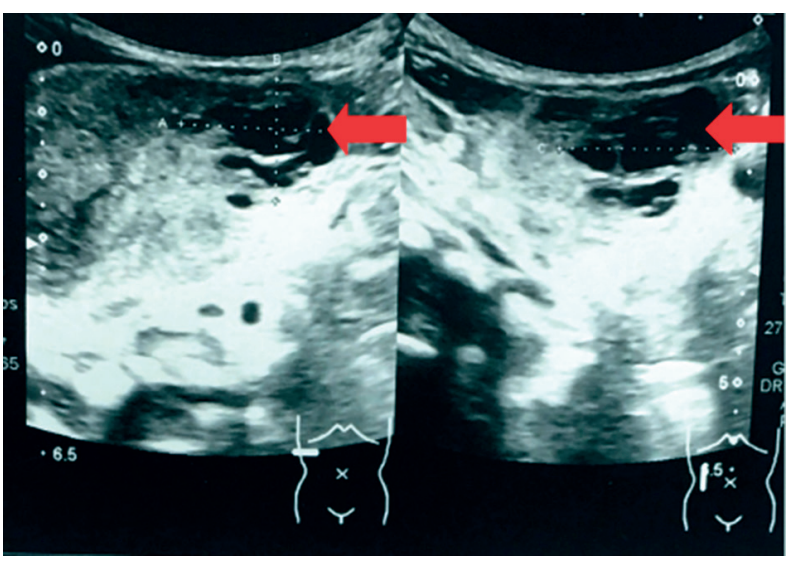

FIGURE 1. Abdominal ultrasound examination: echogenic tumorous mass with cystic lesion of the right kidney. The arrow shows the cystic compartment

cavity. Therefore according to emergency policy, an ultrasonography examination of the abdomen was made. Abdominal ultrasonography showed an echogenic tumourous mass in the right kidney (diameters: $6.0 \mathrm{~cm}$ $\times 3.9 \mathrm{~cm} \times 4.3 \mathrm{~cm}$ ), as well as cystic lesion in the lower part of the right kidney (diameters: $2.7 \mathrm{~cm} \times 3.0 \mathrm{~cm}$ ) (Figures 1, 2).

In the left kidney slight widening of the renal pelvis and calyces was observed without any major difference in comparison to the normal state. These changes were not described in the previous control prenatal tests.

In the further diagnostic pathway additional tests were performed to characterize the tumour (its position, diameters, possible local metastasis to the abdominal and the pleural cavity). The algorithm is presented in Figure 3.

The chest X-ray and abdomen, MRI of the same regions were made. The chest X-ray did not show any abnormalities. MRI showed bordered tumour localized in the mid-lower part of the right kidney (diameters: $5.2 \mathrm{~cm}$ $\times 4.7 \mathrm{~cm} \times 4.3 \mathrm{~cm}$ ) with the cystic component (diameters: $3.0 \mathrm{~cm} \times 2.0 \mathrm{~cm} \times 3.0 \mathrm{~cm}$ ) (Figure 4). The tumour was lifting the right renal artery towards its upper border. The right renal vein was pushed down by the lower border of the tumour. Furthermore slight hypertrophy of the left kidney was observed. No metastasis was found.

Taking into account the results of all of the prescribed tests the neonate was qualified for surgical treatment according to the emergency policy - right -sided nephrectomy and biopsy of regional lymph nodes. Upper transversal laparotomy at the right side was made under general anaesthesia. The tumour was resected with the right kidney (weight 206 g; Figure 5 A-C) and the biopsy of regional lymph nodes. Samples collected during the surgery were sent for histopathological examination. The examination of the samples revealed congenital mesoblastic nephroma classical type - without a capsule, penetrating in a "finger-like" manner into the parenchyma of the kidney.

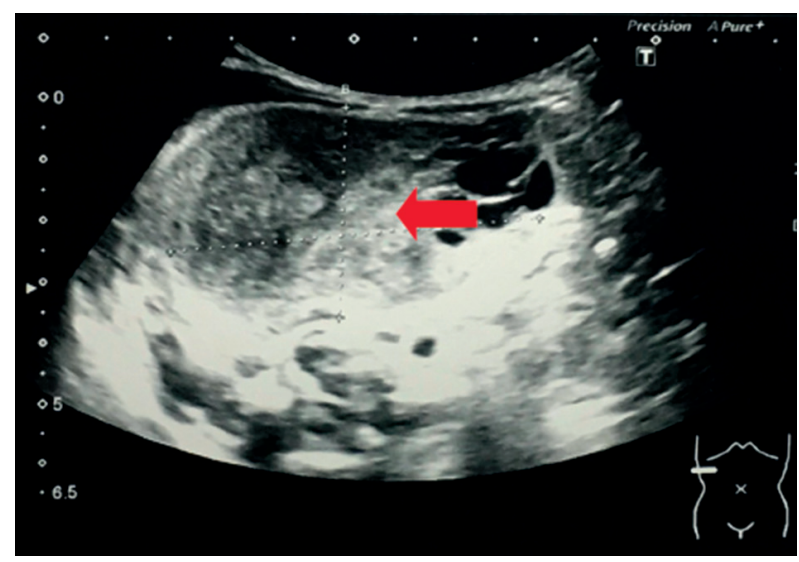

FIGURE 2. Abdominal ultrasound examination: echogenic tumorous mass with cystic lesion of the right kidney. The arrow shows the solid compartment

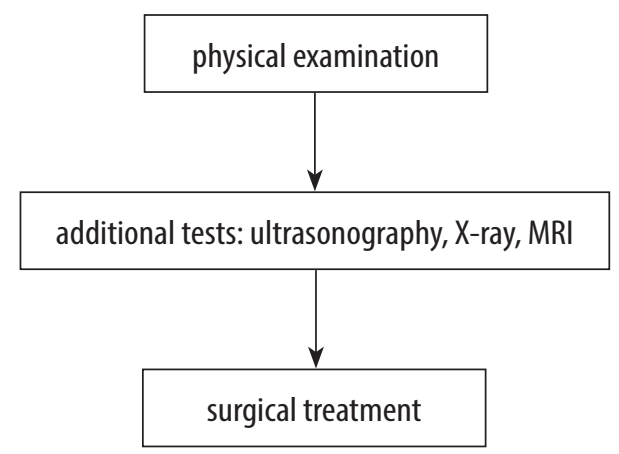

FIGURE 3. The diagnostic algorithm used in presented case.

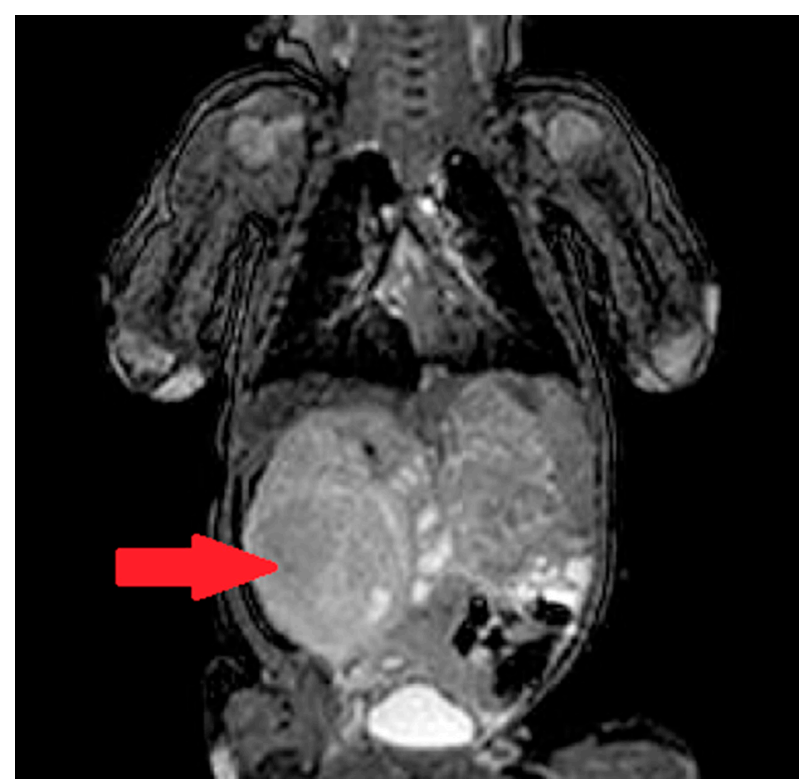

FIGURE 4. MRI: tumor located in the mid-lower part of the right kidney containing the cystic component

The child was readmitted to the Department of Paediatric Surgery to control the wound healing.

Five weeks later the patient was again admitted to the hospital. The child was in general good state. The parents did not observe any alarming signs during the child's stay 

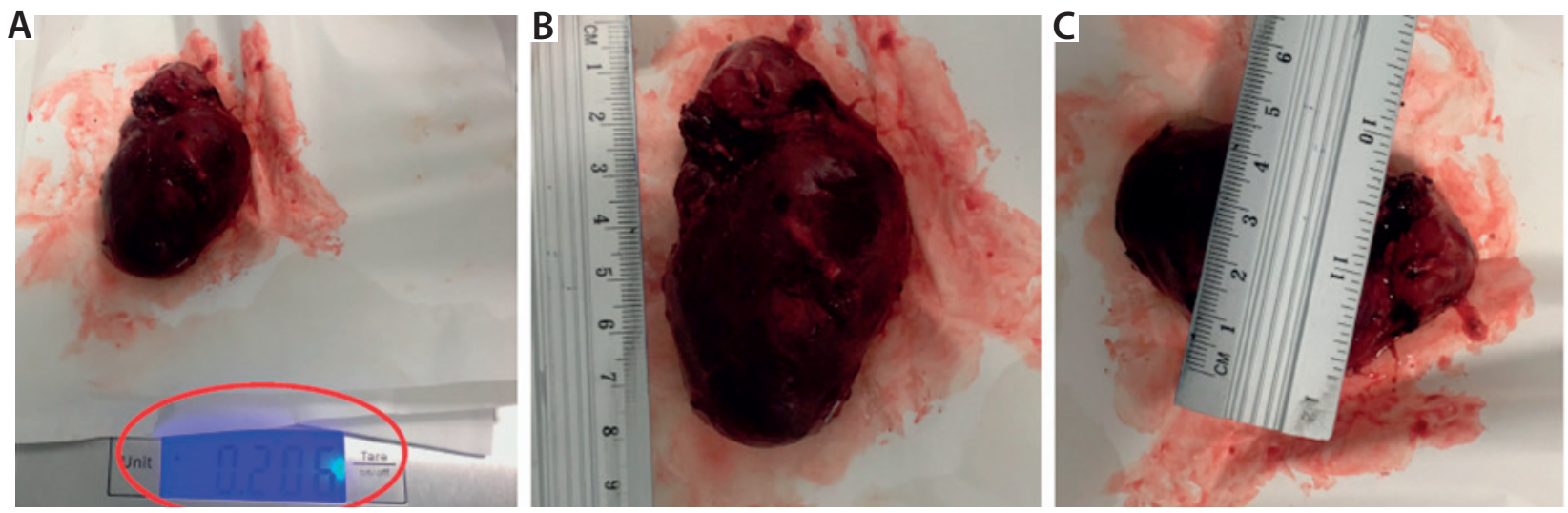

FIGURE 5 A-C. The kidney with the tumor

at home. Physical examination revealed dry, pink skin, fontanelle $(3 \mathrm{~cm} \times 2 \mathrm{~cm})$ in the horizontal plane. On the skin in the area under the right ribs, a transversal healed scar after laparotomy can be seen.

After the consultation of the paediatric surgeon and paediatric oncologist, it was decided that the girl did not require chemotherapeutic treatment.

She remains under the supervision of paediatric surgeons. Ultrasound of the abdomen and laboratory tests are made every 3 months.

\section{DISCUSSION}

Congenital mesoblastic nephroma is one of the most frequent renal tumours in newborns and young infants. However, in the described case no pathology was found in prenatal ultrasound examinations. In the literature we can find information about the use of MRI in the prenatal diagnosis of congenital mesoblastic nephroma [5].

According to the results of the histopathological examination, 3 histologic subtypes are described: classical type, cellular type, and mixed type $[1,4,7]$.

Cellular type is the most common and consists of solid, cellular, sheetlike growth pattern of oval or round cells with little cytoplasm and frequent mitoses and necrosis. The classical variant is characterized by leiomyomatous histology, with spindle cells in bundles, rare mitoses, and absence of necrosis. The mixed type features both classical and cellular morphologies. The risk of recurrence is higher in cases with cellular and mixed types, in children older than 3 months of age, and at stage III of disease resulting from incomplete surgical resection and vascular invasion [1]. A frequent genetic alteration is the translocation $t(12 ; 15)$ resulting in a fusion of the ETV6 gene on 12 p13 and the NTRK3 gene on 15p15, which occurs almost exclusively in cellular MN [4].

The results of the study, which aimed to determine whether imaging findings in children can predict the likely pathological variant, performed by Chaudry et al. suggests that the image of the classic variant include a peripheral hypoechoic ring or large solid component, while cystic/necrotic changes and haemorrhages are much more common in cellular CMN [8]. However, the study group was relatively small [8].

According to Wang et al., a differential diagnosis between CMN and Wilms' tumour is critical to develop the most effective therapeutic approach [9]. It can be challenging because the examination of clinical symptoms and imaging characteristics can be very similar [9]. However, it must be underlined that less than $2 \%$ of patients with Wilms' tumour present at under 3 months of age [9]. The findings that suggest rather Wilms' tumour are tumours with congenital syndromes or anomalies, and the presence of bilateral tumours [9].

Most children with CMN have an excellent prognosis and are treated with radical nephroureterectomy with lymph node sampling. Neoadjuvant chemotherapy is recommended only if the lesion is inoperable [10].

Gooskenes et al. paid attention to the fact that newborn patients with CMN deserve special attention with respect to the timing and type of treatment because the risk of treatment-related mortality (both surgery- and chemotherapy-related) is relatively high in the first weeks of life [11].

However, cases with CMN growing to the hilar and perirenal soft tissue were described with possible metastasis to the lung, liver, brain, and heart $[10,12,13]$. That is why oncological surveillance is needed (ultrasound of the abdomen and laboratory tests are made every 3 months).

According to Jehangir et al., recurrence and metastasis in cellular CMN are much more common than described earlier and carry a high mortality; children with cellular and mixed CMN require close clinical and radiological follow-up for a minimum of 12 months after primary surgery [10].

\section{CONCLUSIONS}

The presented case report confirms high rate of potentially benign CMN. Prompt surgery is well-tolerated and is the treatment of choice. In case of complete resection post-operative treatment is unnecessary. Careful check- 
up with ultrasound is mandatory due to the tendency of CMN to recur locally.

\section{DISCLOSURE}

The authors declare no conflict of interest.

\section{REFERENCES}

1. Coran AG, Caldamone A., Adzick NS, et al. Pediatric Surgery, 2-Volume Set 7th Edition. Mosby, 2012.

2. Bozlu G, Çitak EÇ; Evaluation of renal tumors in children. Turk J Urol 2018; 44: 268-273.

3. Mandal KC, Mukhopadhyay M, Barman S, et al. Uncommon renal tumors in children: A single center experience. J Indian Assoc Pediatr Surg 2016; 21: 61-65.

4. Vokuhl C, Nourkami-Tutdibi N, Furtwängler R, et al. ETV6NTRK3 in congenital mesoblastic nephroma: A report of the SIOP/ GPOH nephroblastoma study. Pediatr Blood Cancer 2018; 65 (4).

5. Cass DL. Fetal abdominal tumors and cysts. Transl Pediatr 2021; 10: $1530-1541$.

6. Alamo L, Beck-Popovic M, Gudinchet F, et al. Congenital tumors: imaging when life just begins. Insights Imaging 2011; 2: 297-308.

7. Tripathy PK, Behera S, Mohanty HK. Cellular Congenital Mesoblastic Nephroma in a Newborn. J Neonatal Surg 2017; 6: 45.

8. Chaudry G, Perez-Atayde AR, Ngan BY, et al. Imaging of congenital mesoblastic nephroma with pathological correlation. Pediatric Radiology 2009; 39: 1080-1086.

9. Wang ZP, Li K, Dong KR, et al. Congenital mesoblastic nephroma: clinical analysis of eight cases and a review of the literature. Oncology letters 2014; 8: 2007-2011.

10. Jehangir S, Kurian JJ, Selvarajah D, et al. Recurrent and metastatic congenital mesoblastic nephroma: where does the evidence tand? Pediatr Surg Int 2017; 33: 1183-1188.

11. Gooskens SL, Houwing ME, Vujanic GM, et al. Congenital mesoblastic nephroma 50 years after its recognition: a narrative review. Pediatric Blood Cancer 2017; 64: e26437.

12. Patel Y, Mitchell CD, Hitchcock RJ. Use of sarcoma-based chemotherapy in a case of congenital mesoblastic nephroma with liver metastases. Urology 2003; 61: 1260.

13. Boithias $\mathrm{C}$, Martelli H, Destot-Vong KD i wsp.; Conduite à tenir obstétricopédiatrique devant la découverte anténatale d'une masse hyperéchogène rétropéritonéale. Arguments en faveur d’un néphrome mésoblastique congénital [Management of antenatal fetal abdominal tumors. Clues for the diagnosis of a congenital mesoblastic nephroma]. J Gynecol Obstet Biol Reprod (Paris) 2009; 38: 277-285. 
